\title{
The way we write
}

“Whatever we well understand we express clearly, and words flow with ease..."

Nicolas Boileau-Despréaux, L'Art Poétique (1674)
Scientific articles are difficult to read, even for scientists. The use of jargon is a common affliction but not the only culprit. Poor word choice, convoluted stylemeant to sound 'professional' — and even blatant lack of a story line often share the blame. The prevalence of poor scientific writing is a problem for an interdisciplinary journal such as Nature Methods, but first and foremost for scientists.

In research, where success is widely measured in terms of publications, poor writing skills are an obstacle in one's career path. First, a paper must pass the filters of editorial and peer review. Then, to have an impact once published, a contribution must be read by peers who will build upon the new insight. Generally editors and reviewers genuinely attempt to focus on the science and not on the style. But bad writing can have such pernicious effects as to obscure the scientific method or the conclusions. With competition for space in journals and with reviewers pressed for time, writing quality will sometimes tip the balance.

Yet despite the undisputed importance of publication in a scientist's career, very little is done to prepare young investigators to clearly report their results. Apparently, people believe that because every scientist can write, every one of them will be able to write good scientific prose. Well, everyone can sing, but many of us do not exercise our vocal cords outside the morning shower-and for good reasons.

Imagine a postdoc who has learned English as a second or third language, and is expected - without specific training - to write a scientific paper. If this image does not speak to you, imagine yourself entering the stage of Carnegie Hall with only your repertoire of nursery rhymes and shower singing exercises. Why are we, as a community, asking each new generation to base such an important part of their career on a skill that we have not helped them hone?

Don't get me wrong: non-native English speakers face an additional difficulty, but native speakers are not immune to the plague of bad prose. In fact, a fair number of papers we receive from non-native English speakers are above average in terms of writing. Perhaps this is because these authors tend to seek simplicity and put special care in what they see as a difficult task. The range of quality is also, we suspect, a reflection of the grammar instruction they received in their native language.

Some will argue that writing is a talent and cannot be taught—countless music lessons don't make an opera star. But this is not about making a best-selling novelist out of every graduate student. Scientific writing is a craft, with its own set of principles and strategies that can be learned. Like its creative and reporting counterparts, scientific writing has its experts and its reference books with advice, specific examples and useful exercises (see Zeiger, M. Essentials of Writing Biomedical Research Papers $2^{\text {nd }}$ edn.; McGraw-Hill, New York, 2000).

Yet there is little structure in place to bring this teaching to those who need it most. Some commendable universities offer a scientific writing course, but it is usually not part of the curriculum and accommodates only a fraction of the students; others have workshops or tutoring centers. Students on the vast majority of campuses where nothing of the sort is available often depend upon the teaching instinct of their supervisor.

This additional coaching responsibility is unfair for the research mentors, who already have a long list of duties and are not trained to teach writing. They may even have false impressions about the conventions of scientific prose-the misleading recommendation of using the passive voice is a common example. Moreover, time is an important factor and many supervisors will write the papers themselves if students are not up to the task.

The international scientific community should tackle the problem at the source and make scientific writing an integral part of the graduate curriculum. All graduate students, regardless of their native language, should attend classes focusing on the specifics of this writing genre in English. Qualified instructors should teach these courses over long-enough periods to effectively make use of exercises and homework. Also, they should base the teaching on real examples and engage students with assignments about their own research projects.

As a community, scientists have a responsibility in shaping the graduate curriculum to prepare students for the challenges of a career. Teaching them how to clearly convey their work in writing is, in our view, a priority too often neglected. Leaving this to your pondering, we thank you for reading this page and ask you to forgive the mistakes of style it undoubtedly contains. After all, this Editor is a scientist and a non-native English speaker, and there is only so much an excellent copyeditor can do. 